\title{
Interview: Katherine Richardson
}

\section{A climate congress in March aims to update the assessment of global warming. Olive Heffernan talks to the meeting's chair about the tasks that lie ahead.}

I n December, world leaders will gather in Copenhagen with the agenda of agreeing a global deal on regulating greenhouse gas emissions to avoid dangerous climate change. Negotiators at the UN meeting will base their decisions on the last scientific assessment from the UN advisory body, the Intergovernmental Panel on Climate Change (IPCC), but by then the report will be well past its sell-by date.

With a mission of updating the existing knowledge on climate change, the world's top climate experts will come together at the International Scientific Congress on Climate Change held 10 to 12 March in Copenhagen. Marine scientist Katherine Richardson, from the University of Copenhagen, is chairing the congress.

How did this event come about? The idea for this congress was born in discussions with the Danish government, host of the UN meeting that is going to happen here in Copenhagen in December. The negotiations there will, of course, be based on the latest IPCC report, but they're going to be missing the last four years of research results.

The strength of the IPCC report is that it's based on consensus, and as such it can be used as a starting point for negotiations - but that's also its weakness. It takes a long time to reach consensus, and the report from 2007 doesn't include any results published later than 2005. Exactly the same problem occurred in the UK in 2005 when there was a G8 summit right in the middle of an IPCC reporting period. A meeting was held in Exeter to update the science. So I think that is where the original idea for this congress came from. A group of the world's leading research institutes, including the University of Copenhagen, discussed with the Danish government whether we could reach out to the scientific community with a meeting that pulls together the latest scientific results, and we took on the challenge.

Who will be at the congress in March? I've been overwhelmed by the response from the scientific community. We have over 1,600 scientific abstracts from over
70 countries organized into 58 different sessions, which span the breadth of the humanities and the social and natural sciences. The economy is going to be a major issue here - we've got both former UK government advisor Lord Nicholas Stern and economist William Nordhaus from Yale. People have said to me, "Well, you realize they don't agree with each other?" Yes, I realize that, but if we don't get them into the same room and hash some of these things out then we're not going to get anywhere, are we? Similarly, there will be one session on the potential and limitations for biofuels. We can't have one session saying that biofuels for transportation are the greatest thing since sliced bread and another that says that biofuels are deeply problematic because they use too much water, so the scientists will simply have to work it out until they arrive at a balanced overview of our knowledge on that front.

What does the congress hope to achieve? Whereas the IPCC won't look at something unless it's been published, we're letting people come here with their newest results. One product to come out of this will be a good old-fashioned book aimed at academics and thick enough to hold a door open. That will be out in 2010. But we're also producing a 30-page synthesis report in words that everyone can understand. That will come out by 1 June and will be used to target the participants of the UN conference in December and the media.

\section{How will this differ from the IPCC process?}

The knowledge that we have now as scientists makes the problem even more urgent than it was in 2007. This meeting will look at the surprises and the new knowledge that have emerged since the 2007 IPCC report. A committee will sketch out a draft of the 30-page synthesis document based on the most important messages from each of the 58 sessions. This will be completed by 1 May, at which stage it will be reviewed by, among others, the Earth System Science Partnership for publication in June. So it will be scientifically reviewed, but it won't have the political vetting that the IPCC report has. The report cannot be seen as an official paper of the UN conference in December because it isn't part of the political system. But I'm hoping that it will have an effect

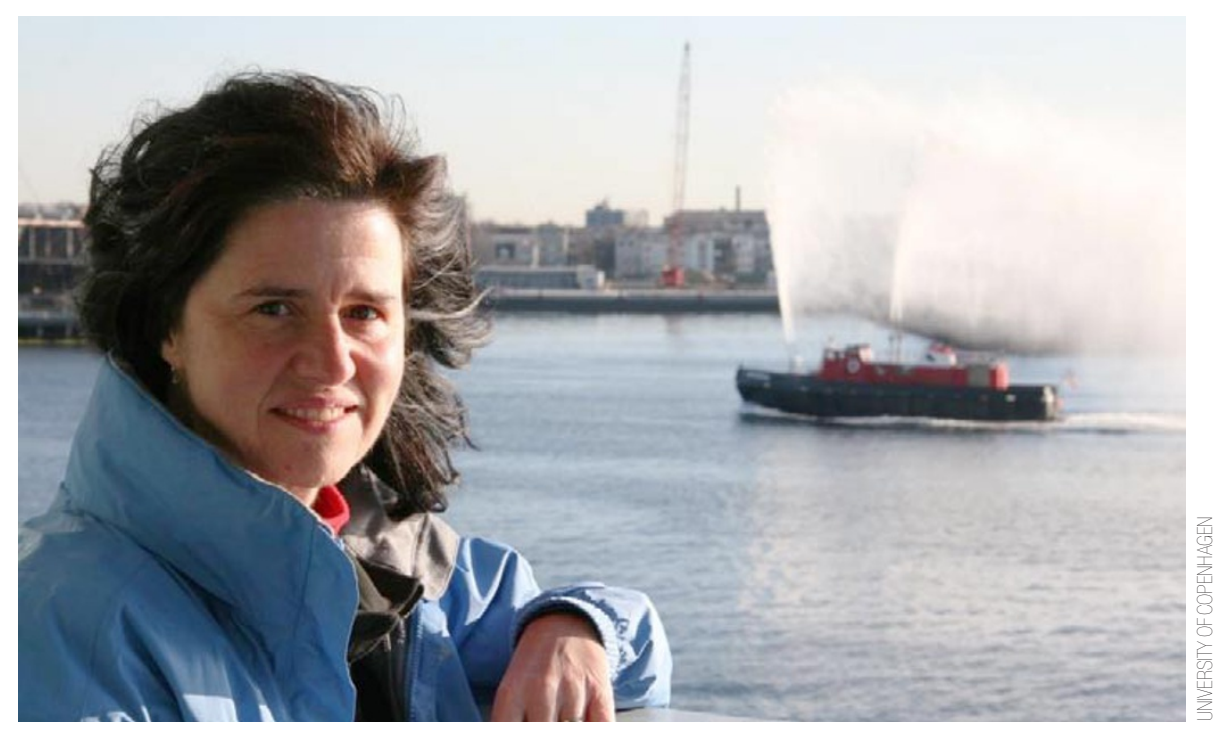


on society. I see this as a chance to get the sense of urgency out and to influence the negotiations.

\section{The strength of the IPCC report is that it's based on consensus - but that's also its weakness. It takes a long time to reach consensus.}

\section{What new results do you expect?}

Lots of new research has come out on sea level rise since the last IPCC assessment, and our knowledge of tipping points - chances of dramatic and sudden changes in the system - is now much greater. As a natural scientist, I would like to see more understanding of the actual Earth system on the programme. But we planned this congress with negotiators in mind who have responsibility for charting the future course of countries through this problem. If I was in that position, I would want to feel that I had struck the right balance between how much I tried to actively combat this problem and how much I simply accepted present and coming change. Therefore, two major themes in the congress are mitigation and adaptation. The only reason to have natural science in there is because you need to know what it is you're adapting to or why it is imperative to prevent something from happening.

What are the chances of reaching a global deal this year?

Whatever happens in Copenhagen in December, it's not going to be enough. There's no doubt about that. It's not going to be enough in the same way that the goals for reducing $\mathrm{CO}_{2}$ emissions in the $\mathrm{EU}$ are simply not enough. Reducing emissions by 20 per cent by 2020 means we'll still be highly dependent on fossil fuels and that the atmospheric $\mathrm{CO}_{2}$ concentrations will still be rising steadily. But for me a global agreement is absolutely alpha and omega, because at least then there will be a framework to work within, which we can make tighter and stronger as time goes on. I won't say that I don't care what's in it, because I would love it to go as far as it can go, but the main thing for me is that we get a global agreement — and I believe that we will.

\section{So, will we be able to prevent a climate crisis?}

I'm an optimist, and I think we are going to crack this one. We're the first generation that has realized this problem, and so we are the first generation that can do something about it. We're in the process of doing it now. To solve the climate problem you need to have industry, the research community and the political system working together, and I see them converging on this. I was trained as a scientist never to sit down with politicians - to throw your results down and run away, and not to get your hands dirty. But there's general acceptance now among really good scientists that this problem is so serious that we need to work together. And that gives me hope.

Published online: 5 March 2009

doi:10.1038/climate.2009.25

Olive Heffernan is editor of Nature Reports Climate Change.

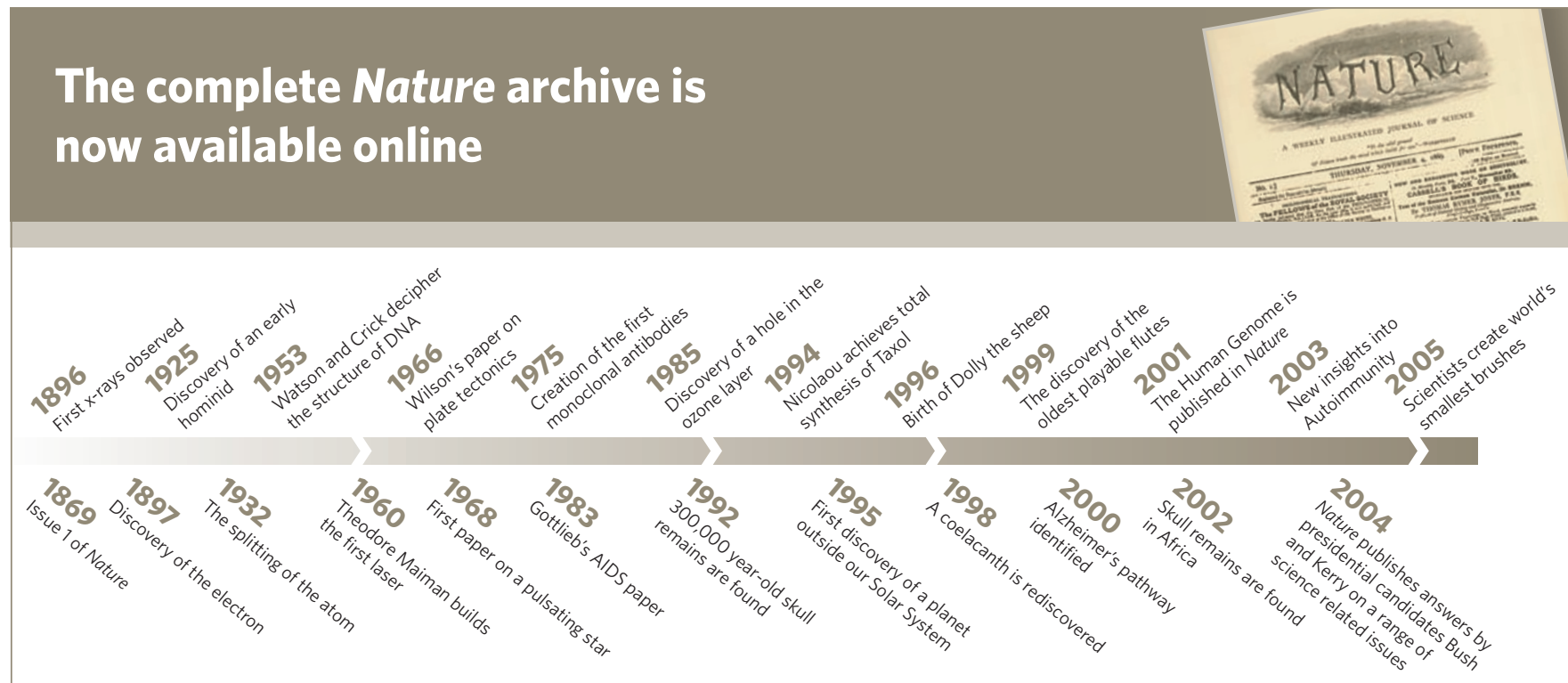

Nature's archive is the history of science. Since launch in November 1869, Nature has published many of the most significant and influential papers in modern science. Articles are published in PDF with HTML abstracts.

You can search by author, affiliation or citation, or simply browse by issue. All articles can be searched from www.nature.com
Full text access to the article is available with a site license. Ask your Librarian or information manager about site license access. Individual articles can also be purchased online.

Are you interested in Nature's history?

For video interviews, articles, and timelines, visit www.nature.com/nature/history. 